




\section{Governo Federal \\ Ministério da Economia \\ Ministro Paulo Guedes}

\section{2 a Instituto de Pesquisa}

Fundação pública vinculada ao Ministério da Economia, o Ipea fornece suporte técnico e institucional às ações governamentais possibilitando a formulação de inúmeras políticas públicas e programas de desenvolvimento brasileiros - e disponibiliza, para a sociedade, pesquisas e estudos realizados por seus técnicos.

\section{Presidente}

Carlos von Doellinger

Diretor de Desenvolvimento Institucional, Substituto Manoel Rodrigues dos Santos Junior

\author{
Diretor de Estudos e Políticas do Estado, \\ das Instituições e da Democracia \\ Alexandre de Ávila Gomide
}

Diretor de Estudos e Políticas Macroeconômicas

José Ronaldo de Castro Souza Júnior

Diretor de Estudos e Políticas Regionais, Urbanas e Ambientais

Aristides Monteiro Neto

\author{
Diretor de Estudos e Políticas Setoriais de Inovação \\ e Infraestrutura, Substituto \\ Bruno César Pino Oliveira de Araújo \\ Diretora de Estudos e Políticas Sociais \\ Lenita Maria Turchi \\ Diretor de Estudos e Relações Econômicas e \\ Políticas Internacionais \\ Ivan Tiago Machado Oliveira
}

\section{Assessora-chefe de Imprensa e Comunicação} Mylena Pinheiro Fiori

Ouvidoria: http://www.ipea.gov.br/ouvidoria URL: http://www.ipea.gov.br

\section{RADAR}

\section{Tecnologia, produção e comércio exterior}

\author{
Editores Responsáveis \\ Graziela Zucoloto e Pedro Miranda
}

Radar : tecnologia, produção e comércio exterior / Instituto de Pesquisa Econômica Aplicada. Diretoria de Estudos e Políticas Setoriais de Inovação e Infraestrutura (Diset). - n. 1 (abr. 2009) - . Brasilia : Ipea, 2009-

Quadrimestral

ISSN: 2177-1855

1. Tecnologia. 2. Produção. 3. Comércio Exterior. 4. Periódicos. I. Instituto de Pesquisa Econômica Aplicada. Diretoria de Estudos e Políticas Setoriais de Inovação e Infraestrutura (Diset).

CDD 338.005

C Instituto de Pesquisa Econômica Aplicada - ipea 2019

As publicações do Ipea estão disponíveis para download gratuito nos formatos PDF (todas) e EPUB (livros e periódicos).

Acesse: http://www.ipea.gov.br/portal/publicacoes

As opiniões emitidas nesta publicação são de exclusiva e inteira responsabilidade dos autores, não exprimindo, necessariamente, o ponto de vista do Instituto de Pesquisa Econômica Aplicada ou do Ministério da Economia.

É permitida a reprodução deste texto e dos dados nele contidos, desde que citada a fonte. Reproduções para fins comerciais são proibidas. 


\section{SUMÁRIO}

APRESENTAÇÃO

FINANCIAMENTO DO DESENVOLVIMENTO NO BRASIL

João Alberto De Negri

Bruno César Araújo

Ricardo Bacelette

Dea Fioravante

Denise Leyi Li

Bernardo Furtado

COMPARAÇÕES INTERNACIONAIS DE BANCOS

DE DESENVOLVIMENTO

11

Bruno César Araújo

Ricardo Bacelette

ELASTICIDADE-JUROS E PRAZO DA DEMANDA DE CRÉDITOS LIVRE E DIRECIONADO NO BRASIL

17

João Alberto De Negri

Patrick Franco Alves

Sergio Mikio Koyama

Bruno César Araújo

IMPACTOS DO CRÉDITO DIRETO DA FINEP NO ESFORÇO

DE P\&D DAS FIRMAS BENEFICIÁRIAS

21

André Rauen

Cayan Saavedra

Newton Hamatsu

7 



\section{APRESENTAÇÃO}

Esta edição $\mathrm{n}^{\mathrm{o}} 59$ do boletim Radar: tecnologia, produção e comércio exterior sintetiza alguns dos resultados apresentados no livro Financiamento do Desenvolvimento no Brasil, publicado pelo Ipea, além de trazer reflexóes e análises adicionais.

No artigo introdutório, Financiamento do desenvolvimento no Brasil, João Alberto De Negri, Bruno César Araújo, Ricardo Bacelette, Dea Fioravante, Denise Leyi Li e Bernardo Furtado apresentam indicadores do mercado de capitais brasileiros, discutem a participação dos créditos livre e direcionado no país, e refletem sobre as justificativas econômicas para a intervenção do governo no mercado de crédito, via bancos públicos. Ainda, os resultados do estudo sintetizado no artigo constatam que a eliminação do custo de participação no mercado de crédito aumentaria o PIB per capita em 7\%, por meio do crescimento da participação das firmas com crédito no mercado.

$\mathrm{O}$ artigo Comparaçóes internacionais de bancos de desenvolvimento, de Bruno César Araújo e Ricardo Bacelette, identifica um grupo de países que pode servir como base para comparaçóes com o Brasil no que tange à importância dos bancos de desenvolvimento (BDs). Esse grupo é heterogêneo quanto à renda per capita, mas situa grandes países de renda média - Brasil, China, Turquia e Índia - ao lado de grandes países desenvolvidos, como Estados Unidos e Alemanha. Os autores reforçam que, a despeito de diferenças histórico-institucionais importantes, esses países são unidos pela alta participação dos BDs em suas economias.

Em Elasticidade-juros e prazo da demanda de créditos livre e direcionado no Brasil, João Alberto De Negri, Patrick Franco Alves, Sergio Mikio Koyama e Bruno César Araújo analisam as contrataçóes de créditos livre e direcionado de 378.651 empresas no Brasil, no período 2004-2017. O banco de dados elaborado, que associa informações de diversas instituições, inclui informaçóes por operação de crédito, empresa, banco, modalidade do crédito, origem dos recursos, no mês e ano da contratação. $\mathrm{O}$ trabalho traz uma contribuição singular à literatura brasileira porque, além de identificar as variáveis que afetam a demanda de créditos livre e direcionado para as empresas brasileiras, identifica variáveis que caracterizam a relação entre esses dois mercados de crédito.

Esta edição finaliza com o artigo de André Rauen, Cayan Saavedra e Newton Hamatsu, intitulado Impactos do crédito direto da Finep no esforço de P\&D das firmas beneficiárias. $\mathrm{O}$ estudo debate em que medida o crédito direto da Finep impacta o esforço tecnológico das firmas beneficiárias. Em suma, em razão da tomada de crédito, as firmas beneficiárias somam recursos próprios àqueles obtidos com o Estado ou apenas substituem os recursos próprios, que já seriam investidos, pelos recursos públicos? Os autores concluem que, ainda que firmas beneficiárias e não beneficiárias tenham aumentado seu esforço tecnológico, no primeiro caso este aumento foi mais expressivo, o que indica um resultado positivo da intervenção.

Esta edição do boletim Radar visa, mais uma vez, colaborar com o debate público e contribuir na avaliação e na formulação de políticas públicas. 



\title{
FINANCIAMENTO DO DESENVOLVIMENTO NO BRASIL ${ }^{1}$
}

\author{
João Alberto De Negri² \\ Bruno César Araújo 3 \\ Ricardo Bacelette ${ }^{4}$ \\ Dea Fioravante ${ }^{5}$ \\ Denise Leyi Li ${ }^{6}$ \\ Bernardo Furtado ${ }^{7}$
}

\section{POR UMA REVISÃO DO FINANCIAMENTO AO DESENVOLVIMENTO NO BRASIL}

A disponibilidade de poupança para financiar o investimento é uma variável-chave para o aumento da produtividade da economia brasileira. Entretanto, o Brasil sofre de um duplo problema: além da baixa taxa de poupança, o país possui um sistema de intermediação financeira repleto de distorçóes. A carência de financiamento de longo prazo e a ineficiência do mercado de crédito no Brasil elevam os juros e o custo dos investimentos em capital e inovação, implicando produtividade menor.

Além do nível, o tipo de investimento é crítico para o crescimento da renda per capita. Não basta apenas aumentar o investimento em relação ao produto da economia, deve-se investir em ativos e atividades com maior impacto sobre a produtividade. No Brasil, recuperar e ampliar a infraestrutura, investir em inovação, ciência e tecnologia e educação depende de um mercado de crédito compatível com as necessidades de crescimento mais acelerado.

\section{DIAGNÓSTICO: O MERCADO DE CAPITAIS BRASILEIRO E POUPANÇA}

As evidências internacionais mostram que o desenvolvimento de um sistema de intermediação financeira é uma pré-condição para o desenvolvimento de um país. Nesse sentido, comparaçóes internacionais demonstram que o Brasil é muito mal posicionado no que tange ao indicador de profundidade financeira (financial deepness, que mede a parcela do crédito privado sobre o produto interno bruto - PIB). Entre 2013 e 2015, esse indicador situou-se em torno de $50 \%$ do PIB brasileiro, enquanto essa cifra corresponde a $70 \%$ no Chile e na África do Sul e quase $120 \%$ na China. ${ }^{8}$ Apenas um pequeno número de empresas, geralmente de grande porte, consegue livrar-se das restrições de crédito no mercado financeiro brasileiro.

1. Versão atualizada de DE NEGRI, J. A. et al. Financiamento do desenvolvimento no Brasil. In: DE NEGRI, J. A.; ARAÚJO, B. C.; BACELETTE, R. (Orgs.). Desafios da nação: artigos de apoio. Brasília: Ipea, 2018. v. 1, podendo, portanto, conter tabelas, gráficos e passagens literais daquele texto. Os autores agradecem os comentários de Paulo Matos, André Rauen e outros participantes em seminário ocorrido no Ipea em Brasília dia 6 de abril de 2018, sem, contudo, implicá-los nas análises e conclusões aqui apresentadas.

2. Técnico de planejamento e pesquisa na Diretoria de Estudos e Políticas Setoriais de Inovação e Infraestrutura (Diset) do Ipea.

3. Técnico de planejamento e pesquisa na Diset do Ipea.

4. Técnico de planejamento e pesquisa na Diset do Ipea.

5. Bolsista na Diset do Ipea.

6. Bolsista na Diset do Ipea.

7. Técnico de planejamento e pesquisa na Diset do Ipea.

8. GOMES, D. M. Escassez de crédito bancário no Brasil: comparação internacional e evidência recente. 2009. Dissertação (Mestrado em Finanças e Economia Empresarial) - Fundação Getulio Vargas, Rio de Janeiro, 2009. 
Em relação ao setor empresarial, no ano de 2015, entre 74 países no mundo, o Brasil ocupava a 53a posição em capitalização das empresas no mercado de capitais, e o 270 lugar no número de empresas listadas em bolsa (359 empresas). Estes indicadores colocam o Brasil atrás de economias relativamente menores. Por sua vez, o valor médio das ofertas públicas iniciais de ações (IPOs) foi relativamente alto, US\$ 411 milhôes, o que colocava o Brasil na $5^{\underline{a}}$ posição relativa. Portanto, a bolsa de valores brasileira é composta por poucas e grandes empresas. ${ }^{9}$

Enquanto no mundo a renda variável na carteira de fundos de investimento é de aproximadamente 40\%, no Brasil é de $11 \%$. Da carteira de fundos de investimento, $66 \%$ são títulos públicos no Brasil em $2015 .{ }^{10} \mathrm{O}$ problema da escassez de orçamento fiscal faz com que o governo precise competir com o setor privado pela poupança, muitas vezes forçada, e o mercado de capitais vem perdendo sua funcionalidade para financiar o desenvolvimento.

$\mathrm{O}$ atual contexto da economia brasileira sugere um esgotamento do modelo tradicional de financiamento ao desenvolvimento, fortemente baseado na disponibilidade de crédito público. É preciso um novo arranjo entre financiamento público e privado. Não apenas o volume de recursos fiscais não é suficiente para financiar o desenvolvimento na velocidade desejável, mas o crédito direcionado subsidiado tem seu potencial limitado por um círculo vicioso: ele se torna mais atraente para os tomadores à medida que o diferencial de juros em relação à taxa básica da economia cresce, mas a própria cobertura desse diferencial tem um custo fiscal e implica perda de eficácia da política monetária. Ambos os efeitos pressionam a taxa de juros, reforçando o ciclo.

\section{CRÉDITO LIVRE, CRÉDITO DIRECIONADO E O PAPEL DOS BANCOS PÚBLICOS}

O Banco Central do Brasil (BCB) define as modalidades de crédito direcionado como "financiamentos rurais (com taxas reguladas e de mercado), financiamentos imobiliários (com taxas reguladas e de mercado), financiamentos com recursos do Banco Nacional de Desenvolvimento Econômico e Social (BNDES) para infraestrutura, agroindústria, para capital de giro e exportaçóes, microcrédito, e outros créditos direcionados". ${ }^{11}$ Os créditos direcionados são concedidos a partir de recursos direcionados, que são operaçóes de crédito regulamentadas pelo Conselho Monetário Nacional (CMN) ou vinculadas a recursos orçamentários, cujas fontes são provenientes de captaçôes de depósito à vista e de caderneta de poupança, além de fundos e programas públicos.

Metade do crédito no Brasil é direcionado, correspondendo a R \$ 1,54 trilhão em 2016, de acordo com o BCB. Do estoque total de crédito, $24 \%$ foram destinados para pessoa física e $26 \%$ para firmas. A maior parte do crédito direcionado para pessoa física foi o habitacional: $71 \%$ ou $\mathrm{R} \$ 524,8$ bilhôes. Na última década, esse tipo foi o grande responsável pelo aumento do crédito de pessoa física na economia. Além disso, mais de $70 \%$ do mercado de crédito habitacional no Brasil é fornecido pela Caixa Econômica Federal (CEF). No caso do crédito direcionado a firmas, 69\% foram disponibilizados pelo BNDES (em torno de R\$ 552 bilhóes).

O restante dos 50\% da carteira ativa de crédito na economia, em 2016, eram créditos livres. Desses, 26\% foram destinados para pessoas físicas e $24 \%$ para empresas. No caso de pessoas físicas, a maior parte do crédito livre (58\%) era consignado e cartão de crédito e, no caso das empresas, a maior parte (61\%) foi destinada ao comércio exterior e para capital de giro.

Um dos entraves para a expansão do crédito livre é a dificuldade para a execução de garantias no Brasil, que, além de elevadas, não são suficientes para a redução do risco de crédito. Não à toa, consignado, cartão de crédito e comércio exterior figuram entre as principais modalidades de crédito livre. Por um lado, o Brasil é

9. COSTA, R. T. Perspectivas e projeções para a economia e o mercado de capitais. Revista R/, n. 204, jun./jul. 2016. Disponível em: https://bit.ly/2X7JLmC. Acesso em: 12 abr. 2019.

10. ROCCA, C. Financiamento das empresas e do investimento no Brasil. In: SEMINÁRIO FINANCIAMENTO DAS EMPRESAS E DO INVESTIMENTO NO BRASIL, 2017, Rio de Janeiro. Anais [...]. Rio de Janeiro: [s.n.], 2017.

11. BCB - BANCO CENTRAL DO BRASIL. Sistema gerenciador de séries temporais. [S.I.]: [s.d.]. 
um dos países que mais exige garantias para a concessão de crédito (cobertura de garantias de 95\% do crédito, em média), ${ }^{12}$ gerando ineficiências devido à imobilização dos ativos dados como garantias. Por outro lado, isso não tem resultado em redução do risco de crédito, pois as garantias fidejussórias - aquelas por meio de fiança são as únicas capazes de reduzir o componente de risco do spread em empréstimos. ${ }^{13}$

Mesmo nos financiamentos em que o bem encontra-se como garantia da operação, como é o caso da alienação fiduciária, há inúmeras possibilidades recursais que encarecem e tornam lenta a execução, acarretando riscos e custos que são repassados à média das operaçóes. Segundo dados do $\mathrm{BCB}$, os custos relativos à inadimplência respondem por mais da metade do spread do crédito total nos últimos cinco anos, incluindo-se os créditos livres e direcionados. Isso significa que, independentemente do valor e da liquidez, os agentes econômicos sabem da dificuldade de executar uma garantia que não seja oferecida por um fiador.

A expansão do crédito direcionado na economia brasileira, em especial após a crise financeira internacional de 2008, trouxe à tona não apenas a questão da sustentabilidade do modelo de financiamento da economia e sua eficácia, mas também a própria discussão sobre a razão de ser do crédito público direcionado ou subsidiado.

Há justificativas econômicas para a intervenção do governo no mercado de crédito, via bancos públicos. Externalidades positivas e falhas de mercado e de coordenação podem justificar o subsídio a determinadas atividades, que não poderiam ser suficientemente financiadas pelo setor privado. As falhas de mercado têm duas consequências no mercado de crédito: $i$ ) o setor privado pode não conceder crédito a estas atividades sob nenhuma condição, o que caracterizaria um cenário de repressão financeira; ou ii) ele pode até conceder crédito, mas em condiçôes proibitivas, que inviabilizariam projetos socialmente viáveis na ausência de subsídios.

Um caso relevante são as atividades de inovação tecnológica, em que os riscos de desenvolvimento de novas tecnologias são elevados e não há oferta de crédito no mercado livre nem custos adequados para cobrir os riscos de desenvolvimento, mas há benefícios sociais superiores aos benefícios privados, via efeitos demonstração, transbordamento tecnológico, entre outros. Outro caso relevante é o financiamento à infraestrutura, cujos investimentos apresentam uma combinaçáo de externalidades com dificuldades para financiamento de longo prazo e, sobretudo, com falhas de coordenação, pois o provimento de infraestrutura pode viabilizar vários outros investimentos.

Há ainda justificativas também para atuação do setor público quando é necessário aumentar a competição no mercado de crédito ou quando há conjuntura econômica especialmente desfavorável, como durante a crise do mercado financeiro dos Estados Unidos em 2008.

Entretanto, essa intervenção não é livre de problemas potenciais, uma vez que pode resultar em falhas de governo que podem superar as falhas de mercado. ${ }^{14}$ Do ponto de vista microeconômico, as falhas podem ser resultado da falta de foco do crédito público ou de subsídios a agentes ou atividades econômicas que poderiam se financiar de maneira privada.

As intervençôes do governo no mercado de crédito, em geral, assumem duas formas: a equalização de taxas de juros e o direcionamento. Do ponto de vista macroeconômico, há basicamente dois custos decorrentes da equalização de taxa de juros: um de ordem fiscal e outro de política monetária.

O crédito direcionado expandiu-se no período recente basicamente via Tesouro Nacional. Enquanto o BNDES dependia fundamentalmente do Fundo de Amparo ao Trabalhador (FAT), o impacto fiscal era menor, pois a remuneração do FAT é indexada pela taxa de juros de longo prazo (TJLP) e a maior parte dos empréstimos do BNDES era também indexada à TJLP mais um spread até 2009. No entanto, os recursos do Tesouro têm

12. SILVA, N.; ZILBERMAN, E. Restrições financeiras e o PIB per capita no Brasil. Brasília: Ipea, 2016a. (Texto para Discussão, n. 2406).

13. Como, por exemplo, em MARTINS, B.; VIANA, C. Agenda de estudos sobre crédito no Brasil. In: SEMINÁRIO FINANCIAMENTO DAS EMPRESAS E DO INVESTIMENTO NO BRASIL, 2017, Rio de Janeiro. Anais [...]. Rio de Janeiro: [s.n.], 2017.

14. LAZZARINI, S. G. et al. What do state-owned development banks do? Evidence from BNDES, 2002-2009. World Development, v. 66, p. 237-253, fev. 2015. 
o custo financeiro da taxa Selic, tradicionalmente mais alta que a TJLP. A diferença entre o que o BNDES remunera o capital da União (TJLP) e a taxa pela qual a União capta recursos (Selic) pode ser considerada, então, um subsídio implícito ao setor produtivo a ser pago pela Uniáo.

Além deste subsídio implícito, há ainda o subsídio explícito, correspondente às equalizaçóes de taxa de juros correspondentes a programas como o Programa de Sustentação do Investimento (PSI), lançado em 2009. Basicamente, a equalizaçáo é definida como o diferencial entre a taxa de juros para o tomador e o custo da fonte de recursos.

O problema de política monetária diz respeito ao estreitamento dos canais de transmissão. Sob o regime brasileiro de metas de inflação, o governo controla o nível de preços via taxa de juros. O estreitamento dos canais de transmissão da política monetária faz com que o $\mathrm{BCB}$ precise elevar a taxa de juros ainda mais para controlar a demanda porque metade do crédito é direcionado e "escapa" da taxa de juros do Sistema Especial de Liquidação e de Custódia (Selic).

\section{AS MUDANÇAS NO MERCADO DE CRÉDITO E O IMPACTO SOBRE A PRODUTIVIDADE}

Estimativas do Ipea ${ }^{15}$ indicam que o crédito privado com recursos livres na economia tenha passado de $15 \%$ para $30 \%$ do PIB entre 2001 e 2011. Estima-se ainda que o acréscimo de 9,5\% para 15\% do PIB em crédito livre para as firmas tenha gerado um aumento de $1,5 \%$ no PIB per capita em dez anos.

No entanto, o mercado financeiro brasileiro apresenta três restriçóes fundamentais: $i$ ) custo de participação no mercado de crédito, na forma de custos administrativos e outras exigências por parte do emprestador; ii) custo de monitoramento do sistema, associado à inadimplência e ao spread; e iii) custo referente ao limite de endividamento, relativo às garantias. A primeira restrição afeta a margem extensiva (a quantidade de firmas que tomam crédito), enquanto as duas últimas afetam a margem intensiva (volume de crédito das firmas que já estấo no mercado de crédito). Exercícios realizados pelo Ipea ${ }^{16}$ mostram que a eliminação do custo de participação no mercado de crédito aumentaria o PIB per capita em 7\%, via crescimento da participação das firmas com crédito no mercado. Melhorias que afetem o custo de monitoramento gerariam um aumento do PIB per capita em 2,4\% via redução do spread bancário. Contudo, o limite do endividamento é a maior restrição financeira, e a reduçáo das garantias nos empréstimos para níveis de países desenvolvidos elevaria o PIB per capita em 12\%.

15. SILVA, N.; ZILBERMAN, E. Impactos macroeconômicos da expansão do crédito no Brasil: o período 2001-2011. In: ENCONTRO NACIONAL DE ECONOMIA, 44., 2016, Foz do Iguaçu. Anais [...]. Foz do Iguaçu: Anpec, 2016b.

16. Silva e Zilberman (2016a). 


\title{
COMPARAÇÕES INTERNACIONAIS DE BANCOS DE DESENVOLVIMENTO¹
}

\author{
Bruno César Araújo² \\ Ricardo Bacelette ${ }^{3}$
}

\section{INTRODUÇÃO}

Os bancos de desenvolvimento (BDs) nacionais foram criados com a finalidade de resolver falhas de mercado, como externalidades positivas, e falhas de coordenação, o que poderia resultar em determinadas atividades insuficientemente financiadas pelo mercado financeiro privado. Essas falhas de mercado podem levar a uma situação de repressão financeira ou à inviabilização de projetos socialmente viáveis, na ausência de coordenação ou mesmo subsídios. Atividades como inovação tecnológica e investimentos em infraestrutura tipicamente apresentam falhas de mercado.

Nesse sentido, uma gama de países estruturou seus BDs nos moldes em que conhecemos a partir do pós-Guerra, e no Brasil não foi diferente. Em 1953 foi criado o Banco Nacional de Desenvolvimento Econômico (BNDE), sigla à qual foi acrescido o nome Social, em 1982, passando, desde então, a ser denominado BNDES. Ainda, o Brasil conta com mais dois bancos voltados ao desenvolvimento regional - o Banco da Amazônia (Basa), de 1942, e o Banco do Nordeste Brasileiro (BNB), de 1952. Além desses bancos regionais, a Caixa Econômica Federal (CEF) tem um papel preponderante no financiamento à habitação, em especial a voltada a camadas mais populares, constituindo-se, assim, um BD nesse braço de suas atribuiçôes como banco múltiplo.

No Brasil tem havido um debate sobre o recente crescimento da participação dos BDs na economia, notadamente do BNDES. Entretanto, salvo poucas exceçôes, ${ }^{4}$ este debate não é formatado em termos internacionais. Entende-se que cada país tem um processo de desenvolvimento institucional próprio. Mas, em que medida é possível comparar os BDs brasileiros com os do resto do mundo? Para responder a essa pergunta, este estudo contribui para essa literatura a partir de uma taxonomia dos BDs segundo critérios quantitativos.

\section{IDENTIFICAÇÃO, FUNÇÕES E CARACTERÍSTICAS DOS BANCOS DE DESENVOLVIMENTO}

A partir da definição exposta na introdução - a de BDs como formas/mecanismos para solução de falhas de mercado -, do ponto de vista empírico não há definição exata para classificar o que seria ou não um BD. No entanto, o Banco Mundial identificou, no ano de 2012, cerca de noventa instituiçóes que se enquadram

\footnotetext{
1. Este artigo é uma versão resumida de ARAÚJO, B. C.; BACELETTE, R. 0 perfil e o papel exercido pelos bancos de desenvolvimento nacionais: análises comparativas internacionais. In: DE NEGRI, J. A.; ARAÚJO, B. C.; BACELETTE, R. (Orgs.). Financiamento do desenvolvimento no Brasil. Brasília: Ipea, 2018, podendo, portanto, conter passagens literais daquele texto. Novamente, os autores agradecem a João De Negri e André Rauen pelos comentários e contribuições valiosas para este estudo e, igualmente, agradecem a Gabriel Faria pelo apoio estatístico e de processamento de dados para este trabalho, sem implicá-los em eventuais erros e omissões.

2. Técnico de planejamento e pesquisa na Diretoria de Estudos e Políticas Setoriais de Inovação e Infraestrutura (Diset) do Ipea.

3. Técnico de planejamento e pesquisa na Diset do Ipea.

4. Ver ARAÚJO, B. C.; DE NEGRI, J. A. O tamanho do BNDES e resposta à crise: uma comparação internacional. Radar: Tecnologia, Produção e Comércio Exterior, v. 51, p. 7-12, jun. 2017; e GUEDES, A. L. Financiamento do desenvolvimento: pesquisa comparativa dos bancos de desenvolvimento. In: DE NEGRI, J. A.; ARAÚJO, B. C.; BACELETTE, R. (Orgs.). Desafios da nação: artigos de apoio. Brasília: Ipea, 2018. v. 1.
} 
como BDs, das quais 39\% foram criadas em período recente, entre 1990 e 2011, com base em survey realizado com mais de uma centena de instituiçóes autointituladas BDs. ${ }^{5}$

No presente estudo, definem-se BDs como intermediários financeiros que fornecem fundos de longo prazo para projetos com alta externalidade, ou ainda como instituiçóes financeiras orientadas primordialmente a prover financiamento com capitais de longo prazo, cujos benefícios difusos são maiores do que o custo do capital empregado, mas que, no entanto, são subfinanciadas por credores privados. O quadro 1 sintetiza e ilustra algumas das principais funçóes e missóes que podem ser desempenhadas pelos BDs nacionais.

\section{QUADRO 1}

Três dos principais macro-objetivos dos BDs

\begin{tabular}{|c|c|c|}
\hline Objetivos & Atuação ampla: exemplos de policy & Atuação setorial: exemplos de policy \\
\hline $\begin{array}{l}\text { Desenvolvimento econômico: } \\
\text { principal denominador comum } \\
\text { encontrado entre os BDs }\end{array}$ & $\begin{array}{l}\text { Historicamente, os primeiros BDs basearam-se nesse objetivo } \\
\text { lato. Como exemplo, é o caso do Banco Estado no Chile, um } \\
\text { dos primeiros antecedentes de BDs na América Latina, criado } \\
\text { em 1853, com o objetivo de oferecer serviços bancários e de } \\
\text { financiamento para "encorajar o desenvolvimento da atividade } \\
\text { econômica nacional". }\end{array}$ & $\begin{array}{l}\text { BDs podem mirar em setores específicos da economia. BDs } \\
\text { também podem atuar de forma ad hoc para cumprir uma missão } \\
\text { específica, delimitada por um período de tempo predefinido, } \\
\text { como apoiar o processo de privatizações de um país. }\end{array}$ \\
\hline Objetivos sociais & $\begin{array}{l}\text { O BNDES foi um dos primeiros na América Latina a ter como um } \\
\text { de seus objetivos primordiais "buscar maior inclusão social e a } \\
\text { redução das desigualdades regionais e sociais". Não raro, BDs } \\
\text { em país em desenvolvimento incluem critérios sociais em suas } \\
\text { análises de projetos. }\end{array}$ & $\begin{array}{l}\text { Alguns bancos podem concentrar-se especificamente em seu } \\
\text { papel social, em missões como a do Banco de Desenvolvimento } \\
\text { do Conselho Europeu (CEB), criado em 1956, e que constitui a } \\
\text { única instituição financeira europeia vocacionada exclusivamente } \\
\text { para o aspecto social. }\end{array}$ \\
\hline Integração regional & $\begin{array}{l}\text { Os estatutos dos BDs podem incluir, em seu mandato, objetivos } \\
\text { de promover a integração das regiões de um país. Caso notório é } \\
\text { o BNDES, que, entre seus macro-objetivos, busca "o fortaleci- } \\
\text { mento da integração regional, para fins de assegurar a soberania } \\
\text { nacional". }\end{array}$ & $\begin{array}{l}\text { Há casos de BDs que focalizam sua atuação especificamente } \\
\text { no aspecto de desenvolvimento regional, como são os casos } \\
\text { das instituições brasileiras Banco do Nordeste Brasileiro (BNB) } \\
\text { e Banco da Amazônia S.A. (Basa). Há ainda BDs cuja atuação é } \\
\text { especificamente de desenvolver interconexão para o comércio } \\
\text { regional, como são o caso da Comunidade do Caribe (Caricom), } \\
\text { com seu Banco de Desenvolvimento Caribenho, e da Corporação } \\
\text { Andina de Fomento (CAF), ambos atuando em cooperação com } \\
\text { BDs nacionais. }\end{array}$ \\
\hline
\end{tabular}

Fonte: Adaptado de UNITED NATIONS. Economic and Social Council. Rethinking the role of national development banks. New York: Ecosoc/UN, 2005.

Historicamente, pode-se afirmar que houve três grandes ciclos de fundação de BDs. Essa distribuição cronológica não se deu por mero acaso, mas impulsionada por contextos históricos que exerceram papel de choques adversos às economias nacionais e estimularam a criação de BDs. O primeiro ciclo vai até a Segunda Guerra Mundial (12\% dos BDs foram criados nesse ciclo); o segundo ocorreu entre a Segunda Guerra e a transição das economias socialistas (49\%); e, por fim, 39\% dos BDs foram criados durante a última onda, no período pós-Crise Financeira Asiática de 1997.

A Crise Asiática representou uma oportunidade para o processo de internacionalização do Chinese Development Bank (CDB). Isso porque a crise provocou fuga de capitais e ativos em dólares nos países da região, sendo que a maior parte das dívidas dos países estavam indexadas em dólares. Para mitigar os efeitos desse choque, a atuação da China no entorno asiático foi peça central, trocando as dívidas em dólares por dívidas em moeda chinesa (renminbi). Isso não só permitiu a recuperação dos $\mathrm{BDs}$ da região como também deu origem a novos $\mathrm{BDs}$ a partir de capital chinês. ${ }^{6}$ 


\section{COMPARAÇÕES INTERNACIONAIS}

A principal contribuição deste estudo ao debate acerca dos $\mathrm{BDs}$ é o emprego de técnicas quantitativas para agrupá-los. Outros estudos ${ }^{7} \mathrm{o}$ fazem de acordo com critérios ad hoc.

A seleção dos BDs partiu da base de dados Orbis Bank Focus, ${ }^{8}$ na categoria specialized government credit institutions, e outras listas de BDs. ${ }^{9}$ A combinação final dessas listas conta com 116 bancos em 54 países. ${ }^{10}$

Para fins da análise que será feita a seguir, cada "país" é a soma de seus BDs nacionais. No caso brasileiro, consideramos o BNDES, o BNB, o Basa e a carteira imobiliária da CEF - tanto carteira habitacional em si quanto um critério pro rata nos ativos, quando necessário.

A análise quantitativa a seguir tem por base a seguinte estratégia:

- foram selecionadas variáveis referentes a tamanho, nível de desenvolvimento, grau de abertura e participação dos BDs na economia;

- uma análise fatorial foi realizada a fim de agrupar as variáveis acima e criar construtos latentes, como, por exemplo, "nível de desenvolvimento", "participação dos BDs na economia” e outros;

- a partir dessa análise fatorial, realizou-se uma análise de cluster hierárquico.

As variáveis escolhidas foram as seguintes: taxa de investimento como proporção do PIB, o próprio PIB a preços correntes, PIB per capita com paridade do poder de compra, profundidade financeira (total dos ativos do sistema financeiro dividido pelo PIB), índice Herfindahl-Hirschman de concentração no sistema financeiro, grau de abertura (exportaçôes mais importaçôes sobre o PIB), carga tributária sobre o PIB, proporção empréstimos/investimento (total da carteira de empréstimos dos BDs de um país dividido pelo investimento corrente), participação dos BDs no total de ativos financeiros, e participação dos ativos dos BDs no PIB.

A partir de construtos latentes elaborados a partir de análise fatorial, realizou-se uma análise de agrupamentos (cluster). Uma questão fundamental em análise de cluster é a escolha do número de agrupamentos. Há um trade-off claro entre semelhança entre os elementos de um grupo e tratabilidade/relevância analítica: poucos clusters significa síntese, mas os elementos dentro do grupo podem ser muito heterogêneos; quando, ao contrário, o analista escolhe mais grupos, os elementos dentro de um determinado grupo são mais semelhantes, mas se pode chegar a um número muito grande de grupos.

A partir de algumas medidas que podem auxiliar nessa tomada de decisão, pode-se dividir os países em quatro, sete ou dez grupos. Neste caso, a soluçáo de dez clusters coloca o Brasil junto à China, à Índia e à Turquia; a solução de sete clusters situa o Brasil junto aos Estados Unidos, à França e ao Japão, além dos três países anteriores; e a solução de quatro clusters agrega, em um terceiro nível, Itália, Alemanha, Coreia, Noruega e Holanda.

A tabela 1 traz algumas características da solução de quatro clusters, a que agrega todos os países acima mencionados. Nesse nível de agregação, o que une esses países do cluster 4 é o fato de terem grandes BDs, apesar de histórias institucionais e finalidades bem diferentes desses bancos.

\footnotetext{
7. Ver, por exemplo, LUNA-MARTINEZ, J.; VICENTE, C. L. Global survey of development banks. Washington: World Bank, 2012. (Working Paper, n. 5969); MUSACCHIO, A. et al. The role and impact of development banks: a review of their founding, focus, and influence. [S.I.]: [s.n.], 2016; e UNCTAD - UNITED NATIONS CONFERENCE ON TRADE AND DEVELOPMENT. The role of development banks in promoting growth and sustainable development in the South. Genebra: United Nations Publication, 2016.
}

8. Disponível em: https://bit.ly/2lqal08. Acesso em: 12 abr. 2019.

9. Luna-Martinez e Vicente (2012).

10. Essa lista, como também os detalhes metodológicos desta seção, está em Araújo e Bacelette (2018). 
TABELA 1

Características da solução de quatro clusters

\begin{tabular}{|c|c|c|c|c|c|}
\hline Grupo & PIB (US\$ bilhões) & $\begin{array}{l}\text { PIB per capita } \\
\text { PPP (US\$) }\end{array}$ & $\begin{array}{c}\text { Grau de abertura } \\
(\mathrm{X}+\mathrm{M}) / \mathrm{PIB}(\%)\end{array}$ & $\begin{array}{l}\text { Parcela dos } \\
\text { ativos do } \\
\text { BD/PIB }(\%)\end{array}$ & Cluster \\
\hline $\begin{array}{l}\text { Países menos desenvolvidos, com alta participação dos BDs que } \\
\text { tendem a ser pequenas economias abertas. }\end{array}$ & \multirow{2}{*}{108,47} & \multirow{2}{*}{15.516} & \multirow{2}{*}{87} & \multirow{2}{*}{13} & \multirow{2}{*}{1} \\
\hline $\begin{array}{l}\text { Países: Angola, Costa Rica, República Dominicana, Kuwait, Marrocos, } \\
\text { Paraguai, Tailândia, Vietnã, Bielorrússia, Etiópia, Mali. }\end{array}$ & & & & & \\
\hline $\begin{array}{l}\text { Países heterogêneos quanto ao grau de desenvolvimento, com BDs } \\
\text { pequenos, heterogêneo quanto a serem economias pequenas e abertas. }\end{array}$ & \multirow[b]{2}{*}{395,74} & \multirow[b]{2}{*}{28.369} & \multirow[b]{2}{*}{101} & \multirow[b]{2}{*}{3} & \multirow[b]{2}{*}{2} \\
\hline $\begin{array}{l}\text { Países: Áustria, Canadá, Suíça, Espanha, México, Malásia, Polônia, } \\
\text { África do Sul, Bulgária, Barein, Finlândia, Croácia, Hungria, República } \\
\text { Eslovaca, Bolívia, Guatemala, Eslovênia. }\end{array}$ & & & & & \\
\hline $\begin{array}{l}\text { Países menos desenvolvidos, com BDs pequenos e que não tendem a ser } \\
\text { pequenas economias abertas (são, em sua maioria, países populosos e } \\
\text { mais pobres). }\end{array}$ & \multirow[t]{2}{*}{248,99} & \multirow[t]{2}{*}{10.082} & \multirow[t]{2}{*}{49} & \multirow[t]{2}{*}{4} & \multirow[t]{2}{*}{3} \\
\hline $\begin{array}{l}\text { Países: Bangladesh, Egito, Quênia, Paquistão, Colômbia, Equador, } \\
\text { Gana, Cazaquistão, Sri Lanka, Nepal, Peru, Filipinas, Rússia e Tanzânia. }\end{array}$ & & & & & \\
\hline $\begin{array}{l}\text { Países heterogêneos quanto ao grau de desenvolvimento, alta participação } \\
\text { dos BDs, e que não tendem a ser pequenas economias abertas. }\end{array}$ & \multirow{2}{*}{$4.043,77$} & \multirow[b]{2}{*}{36.336} & \multirow[b]{2}{*}{61} & \multirow[b]{2}{*}{21} & \multirow[b]{2}{*}{4} \\
\hline $\begin{array}{l}\text { Países: Brasil, China, Índia, Turquia, França, Japão, Estados Unidos, } \\
\text { Alemanha, Itália, Coreia do Sul, Holanda e Noruega. }\end{array}$ & & & & & \\
\hline
\end{tabular}

Alguns BDs são bastante conhecidos da literatura, como o próprio BNDES, o CDB, o Korean Development Bank (KDB), o KfW da Alemanha ou o Ziraat Bankas da Turquia. No entanto, segundo o critério aqui adotado, os Estados Unidos têm a Fannie Mae (banco imobiliário), assim como a Holanda tem o Bank Nederlandse Gemeenten e o Nederlandse Waterschapsbank, a França tem a Caisse des Dépôts et Consignations, a SFIL e o Banque Publique d'Investissement, e assim por diante. A própria Coreia tem um banco agrícola (Nonghyup Bank), com quase o tamanho do KDB.

Dentre os países mais próximos ao Brasil segundo a análise de cluster, a Índia tem um sistema composto de diversos bancos, cada um com um mandato mais específico: o Industrial Development Bank of India (IDBI), o National Bank for Agriculture and Rural Development (Nabard), o Power Finance Corporation Limited, o Rural Electrification Corporation Limited (REC) e o Indian Railway Finance Corporation Limited.

\section{CONSIDERAÇÕES FINAIS}

Este artigo identificou, a partir de análise da literatura existente e de técnicas estatísticas, um grupo de países que pode servir como base para comparaçóes para o Brasil no que tange à importância dos BDs. Esse grupo é heterogêneo quanto à renda per capita, mas situa grandes países de renda média - Brasil, China, Turquia e Índia - ao lado de grandes países desenvolvidos, como Estados Unidos e Alemanha. A despeito de diferenças histórico-institucionais importantes, o que une esses países é a alta participação dos $\mathrm{BDs}$ em suas economias. De fato, artigo anterior já demonstrou que a reação à crise financeira desses bancos também foi semelhante. A relação entre renda per capita e participação dos BDs na economia não é tão clara. ${ }^{11}$ 
Portanto, sob uma perspectiva internacional, a discussão pura e simples sobre o tamanho dos BDs na economia é pobre, pois há diferentes arranjos institucionais que comportam BDs grandes ou pequenos, com diferentes mandatos, independentemente da renda per capita ou do nível de desenvolvimento. Há contrapartes internacionais para os BDs brasileiros, sobretudo o BNDES, em termos de importância para suas respectivas economias e em relação à reação à Crise de 2008. 



\title{
ELASTICIDADE-JUROS E PRAZO DA DEMANDA DE CRÉDITOS LIVRE E DIRECIONADO NO BRASIL ${ }^{1}$
}

\author{
João Alberto De Negri² \\ Patrick Franco Alves ${ }^{3}$ \\ Sergio Mikio Koyama ${ }^{4}$ \\ Bruno César Araújo 5
}

Este artigo analisa as contrataçôes de crédito livre e direcionado de 378.651 empresas, no período 2004-2017, no Brasil, e está baseado no cruzamento das informaçôes do Sistema de Informaçôes de Crédito (SCR) e do Censo de Capitais Estrangeiros no Brasil, ambas do Banco Central do Brasil (BCB), com dados da Relação Anual de Informaçôes Sociais (Rais), da Secretaria de Comércio Exterior (Secex) e do Instituto Nacional de Propriedade Intelectual (Inpi). A amostra de empresas refere-se aos procedimentos de amostragem do extrato certo das pesquisas anuais do Instituto Brasileiro de Geografia e Estatística (IBGE). ${ }^{6}$ Foram consideradas na amostra todas as empresas que, em qualquer ano, entre 2004 e 2017, tinham trinta ou mais pessoas ocupadas, no caso do setor industrial e da construção civil, e vinte ou mais pessoas ocupadas, no caso do segmento de comércio e serviços, segundo dados da Rais.

O banco de dados considera informaçôes por operação de crédito, empresa, banco, modalidade do crédito, origem dos recursos, no mês e ano da contratação. Foram consideradas 910 milhóes de operaçôes de crédito ativas mensalmente. Para essa amostra de empresas, mais de $90 \%$ do crédito contratado no mercado financeiro brasileiro é crédito livre. A tabela 1 mostra que uma parte importante do crédito contratado é realizada por empresas que combinam, na carteira total de crédito contratado, o livre e o direcionado. Deflacionada a série de dados pelo Índice Nacional de Preços ao Consumidor Amplo (IPCA) e considerado valores reais de 2017 , do total de $\mathrm{R} \$ 11,36$ trilhóes de crédito contratados pelas empresas da amostra, no período 2004-2016, R \$ 5,22 trilhóes foram contratados por empresas que acessaram o mercado de crédito livre e direcionado e $\mathrm{R} \$$ 6,08 trilhóes foram contratados pelas empresas que acessaram apenas o crédito livre. As empresas que acessaram apenas o crédito direcionado realizaram operaçôes de crédito no montante de apenas $\mathrm{R} \$ 59,10$ bilhóes.

A relação entre crédito livre e massa salarial é especialmente maior para as empresas que acessam crédito livre e direcionado no mercado $(1,93)$. Esse indicador é menor para as empresas que acessam apenas crédito livre $(1,45)$. Isso significa que as empresas que compóem a sua carteira com a combinação entre os dois tipos de crédito podem estar mais integradas ao mercado de crédito em mercado, em especial no mercado de crédito livre. Nesse caso, isso pode indicar alguma complementariedade nos mercados de crédito. Corrobora nesta direção também o indicador de que a relação entre crédito direcionado e massa de salário é menor para as empresas que acessam os dois mercados de crédito $(0,44)$ do que para as empresas que acessam apenas crédito direcionado $(0,63)$.

\footnotetext{
1. Os autores agradecem os comentários e as sugestões de Ludmilla Lorrany Mattos Silva, Rafael Lima de Morais e Gabriel Garber.

2. Técnico de planejamento e pesquisa na Diretoria de Estudos e Políticas Setoriais de Inovação e Infraestrutura (Diset) do Ipea.

3. Bolsista na Diset do Ipea.

4. Analista do Banco Central do Brasil (BCB).

5. Técnico de planejamento e pesquisa na Diset do Ipea.

6. Foram consideradas a Pesquisa Industrial Anual (PIA), a Pesquisa Anual de Comércio (PAC), a Pesquisa Anual de Serviços (PAS), a Pesqusia Anual da Construção Civil (Paic) e a Pesquisa Industruial de Inovação Tecnológica (Pintec).
} 
TABELA 1

Crédito livre e direcionado das empresas no Brasil (2004-2016)

\begin{tabular}{|c|c|c|c|c|c|}
\hline \multirow{2}{*}{$\begin{array}{l}\text { Composição da carteira de } \\
\text { crédito das empresas }\end{array}$} & \multirow{2}{*}{$\begin{array}{c}\text { Crédito livre } \\
\text { (R\$ bi) } \\
\text { (A) }\end{array}$} & \multirow{2}{*}{$\begin{array}{l}\text { Crédito direcionado } \\
\text { (R\$ bi) } \\
\text { (B) }\end{array}$} & \multirow{2}{*}{$\begin{array}{c}\text { Massa de salário } \\
(\mathrm{R} \$ \text { bi) } \\
\text { (C) }\end{array}$} & \multicolumn{2}{|c|}{ Crédito/massa de salário } \\
\hline & & & & $\begin{array}{l}\text { Livre } \\
(\mathrm{A}) /(\mathrm{C})\end{array}$ & $\begin{array}{c}\text { Direcionado } \\
\qquad(\mathrm{B}) /(\mathrm{C})\end{array}$ \\
\hline Livre e direcionado & $4.244,50$ & 977,44 & $2.201,08$ & 1,93 & 0,44 \\
\hline Sem crédito & - & - & $1.469,08$ & - & - \\
\hline Só direcionado & - & 59,10 & 93,19 & - & 0,63 \\
\hline Só livre & $6.078,99$ & - & $4.195,52$ & 1,45 & - \\
\hline
\end{tabular}

Fonte: SCR/Bacen e Ipea.

Elaboração dos autores.

Obs.: Valores reais $-I P C A / 2017=100$.

No caso das operaçóes de crédito direcionado das empresas da amostra, a maior parte é proveniente das operaçóes do Banco Nacional de Desenvolvimento Econômico e Social (BNDES) e do Financiamento de Máquinas e Equipamentos (Finame). Os produtos de crédito ofertado pelos bancos privados têm prazos menores e maior flexibilidade de utilização do que aqueles ofertados pelos bancos públicos, que são classificados na sua quase totalidade como operaçóes direcionadas. Neste sentido, focalizar ainda mais os bancos públicos nos projetos de longo prazo e incentivar a expansão de produtos de crédito com maior prazo de maturação com os bancos privados poderia melhorar a acessibilidade de crédito pelas empresas no mercado livre.

Os dados, inicialmente, também reforçam a hipótese de que há restrição de crédito no mercado financeiro brasileiro. Em média, anualmente, 38,62\% das empresas não realizam nenhuma operação de crédito no mercado financeiro, 46,49\% realizaram operaçóes apenas de crédito livre, 1,78\% realiza apenas operaçóes de crédito direcionado e $13,11 \%$ acessaram os dois tipos de crédito, conforme tabela 2. É importante ressaltar, entretanto, que esses percentuais não separam o efeito de oferta e da demanda de crédito, mas sugerem que a hipótese de restrição de crédito é muito plausível, mesmo que uma parte da ausência de firmas no sistema financeiro seja por conta da ausência de demanda. Os dados também demonstram que uma parte não desprezível de empresas que não acessam o mercado financeiro de crédito no Brasil anualmente são exportadoras, aproximadamente 2 mil, ou importadoras, aproximadamente 3 mil.

As empresas que exportam e importam geralmente são mais estruturadas do que a médias das empresas no mercado. É, portanto, singular o fato de que elas não acessem o mercado de crédito mais intensamente. É razoável supor que essas empresas conseguem ter acesso ao mercado externo com mais facilidade, bem como ao mercado de capitais e, por conseguinte, não necessitam do mercado de crédito nacional. O pouco acesso ao mercado de crédito pode ser, em parte, justificado por operaçóes inter ou intracompanhias, como no caso das operaçôes pagamento antecipado (PA), que não se tratam de um instrumento de crédito próprio do sistema bancário brasileiro. Mesmo assim, é surpreendente a quantidade de empresas que não acessam crédito por ano no Brasil.

No caso das empresas de capital estrangeiro no Brasil, observa-se que a grande maioria das que acessam o mercado financeiro brasileiro são empresas que acessam somente o mercado de crédito livre. Apesar das empresas de capital estrangeiro que produzem no Brasil acessarem mais facilmente o mercado de crédito internacional, por conta da sua rede internacional e de suas matrizes, inclusive em condiçóes melhores em termos de juros e prazo do que ofertado no mercado de crédito brasileiro, observa-se que mais de $70 \%$ das empresas estrangeiras instaladas no mercado brasileiro acessam algum mercado de crédito. $\mathrm{O}$ endividamento em moeda local e o risco cambial influenciam a decisão destas empresas. No caso das empresas de capital nacional, esse percentual é de $50 \%$. É relevante levar em conta que o porte, o grau de endividamento e o risco desses dois grupos podem não ser comparáveis diretamente. 
TABELA 2

Número de empresas que acessaram crédito por ano no Brasil (2004-2016)

\begin{tabular}{lrrrr}
\hline Composição da carteira de crédito das empresas & Total & Exportadoras & Importadoras & Estrangeiras no Brasil \\
\hline Livre e direcionado & 34.633 & 2.675 & 3.476 & 311 \\
Sem crédito & 101.987 & 1.985 & 3.036 & 953 \\
Só direcionado & $\mathbf{4 . 6 9 5}$ & 139 & 216 & 20 \\
Só livre & $\mathbf{1 2 2 . 7 6 4}$ & 6.708 & 9.265 & 1.991 \\
\hline
\end{tabular}

Fonte: SCR/BCB e Ipea.

Elaboração dos autores.

As características da mão de obra ocupadas nas empresas mostram que as maiores empresas são aquelas que acessam os dois mercados de crédito, livre e direcionado. Em média, estas ocuparam 153,07 empregados com carteira assinada, no período 2004-1016. As empresas que acessaram somente crédito livre também são relativamente maiores do que as demais e ocuparam 87,29 pessoas com carteira assinada, em média. As menores empresas, que ocupam, em média, 42,75, são geralmente as que não acessam crédito no mercado. As empresas que acessam somente crédito direcionado possuem, em média, 62,32 pessoas ocupadas com carteira. Chama a atenção o fato de 4,3 milhóes de pessoas com carteira assinada estarem vinculadas a empresas que não acessam crédito no mercado em algum ano do período analisado.

TABELA 3

Pessoal ocupado nas empresas que acessam crédito no Brasil (2004-2016)

\begin{tabular}{|c|c|c|c|c|}
\hline \multirow[t]{2}{*}{ Composição da carteira de crédito das empresas } & Pessoal ocupado total & $\begin{array}{c}\text { Pessoal ocupado por } \\
\text { empresa }\end{array}$ & $\begin{array}{c}\text { Profissionais científicos e } \\
\text { pesquisadores }\end{array}$ & $\begin{array}{c}\text { Escolaridade media do } \\
\text { pessoal ocupado }\end{array}$ \\
\hline & Número & Número & $\% /$ total & Anos \\
\hline Livre e direcionado & 5.301 .274 & 153,07 & 1,72 & 9,410 \\
\hline Sem crédito & 4.359 .878 & 42,75 & 1,47 & 9,338 \\
\hline Só direcionado & 292.600 & 62,32 & 0,88 & 9,205 \\
\hline Só livre & 10.716 .324 & 87,29 & 1,81 & 9,545 \\
\hline
\end{tabular}

Fonte: SCR/BCB e Ipea.

Elaboração dos autores.

A escolaridade da mão de obra e o percentual de pessoal ocupado em carreira técnico-científica é uma proxy do nível tecnológico da empresa, e, portanto, da qualidade dos produtos e processos prestados pela empresas. Pode ser observado que o percentual de pessoal ocupado em carreira técnico-científica sobre a mão de obra total da empresa é maior no caso das empresas que acessam apenas o crédito livre (1,81\%) e que acessam os créditos livre e direcionado conjuntamente (1,72\%). Isso indica que as empresas de melhor qualidade conseguem acessar o mercado de crédito e possivelmente elaborar planos de negócios mais consistentes com o pagamento futuro desses empréstimos. Isso se reflete também na escolaridade média do pessoal ocupado nas empresas. Vale ressaltar a baixa escolaridade média e o baixo percentual de empresas que acessam somente crédito direcionado. Cabe observar que o crédito direcionado pode estar concentrado, em alguma medida, em empresas de baixa eficiência, baixo rendimentos de escala e com produtividade inferior à média do setor produtivo.

Este trabalho traz uma contribuiçáo singular e nova na literatura brasileira porque, além de identificar as variáveis que afetam a demanda de créditos livre e direcionado para as empresas brasileiras, identifica variáveis que caracterizam a relação entre esses dois mercados de crédito. Ainda, foram estimadas a elasticidade-juros e a elasticidade-prazo da demanda de crédito nestes mercados com as informaçóes de 378.651 empresas distintas, que possuíam 910 milhóes de operaçóes de crédito ativas mensalmente, no período de 2004 a 2017. Os resultados indicam que a demanda de crédito é juros-elástica, com elasticidade -1,011, e que a elasticidade é maior para o crédito livre, $-1,114$. Foi estimada em $+0,312$ a elasticidade-prazo da demanda de crédito direcionado e em $+0,102$ 
a demanda de crédito livre. Os resultados mostram que os juros são mais importantes na decisão da empresa em contratar crédito livre e os prazos são mais relevantes na contratação de crédito direcionado. A elasticidade cruzada da demanda de crédito livre em relação aos juros do crédito direcionado é de -0,017. A elasticidade cruzada da demanda de crédito direcionado em relação ao crédito livre é de -0,077. As baixas elasticidades cruzadas indicam que os produtos estáo pouco relacionados. A elasticidade cruzada da demanda do crédito livre em relaçáo ao prazo do crédito direcionado foi estimada em -0,113, indicando que a demanda de crédito livre cai quando o prazo do direcionado aumenta. A elasticidade spread da demanda geral de crédito é de -0,235. Empresas de pequeno porte têm quase duas vezes mais dificuldade de acessar crédito direcionado do que para acessar crédito livre. Anualmente, 38,62\% das empresas analisadas não realizaram nenhuma nova operação de crédito no mercado financeiro, 46,49\% realizaram operaçóes apenas de crédito livre, 1,78\% realizou apenas operaçóes de crédito direcionado e 13,11\% acessaram os dois tipos de crédito. 


\section{IMPACTOS DO CRÉDITO DIRETO DA FINEP NO ESFORÇO DE P\&D DAS FIRMAS BENEFICIÁRIAS ${ }^{1}$}

André Rauen²

Cayan Saavedra ${ }^{3}$

Newton Hamatsu ${ }^{4}$

O período compreendido entre os anos 2005 e 2014 foi marcado no Brasil pelo aumento substancial tanto do volume destinado ao fomento à inovação empresarial quanto pelo número de instrumentos com esse fim. Foram criadas isenções fiscais variadas, subvenção para firmas e robustos programas de concessão de crédito, com destaque para o Programa Inova Empresa. Este foi capitaneado pela Financiadora de Estudos e Projetos (Finep) em parceria com o Banco Nacional de Desenvolvimento Econômico e Social (BNDES) e disponibilizou, ao total, recursos da ordem de R \$32,9 bilhóes a serem executados ao longo de vários anos e em benefício de vários setores econômicos.

As fontes de recursos que alimentaram tal instrumento são variadas, mas se destacaram, no então período: i) o Programa de Sustentação do Investimento (PSI); ii) o Fundo de Amparo ao Trabalhador (FAT); iii) os recursos próprios de outras operaçóes de crédito; iv) os recursos do Fundo Nacional de Desenvolvimento Científico e Tecnológico (FNDCT); e $v$ ) os recursos do Fundo para o Desenvolvimento Tecnológico das Telecomunicaçóes (Funttel). Nesse contexto, a política de crédito tanto da Finep quanto do BNDES variou, de forma significativa, nos anos analisados; contudo, ela sempre foi marcada por: concessão de recursos a taxas inferiores ao mercado; exigência diferenciada de garantias; carência mais elevada; e inovadora engenharia financeira voltada à mitigação do risco e da incerteza próprios do processo de inovação. O gráfico 1 apresenta a evolução do desembolso do crédito público (direto e indireto) a projetos de inovação no Brasil e nele é possível observar que, devido a um aumento substancial dos desembolsos, principalmente da Finep, o ano de 2014 marca o auge do ciclo de expansão.

\section{GRÁFICO 1}

Crédito à inovação segundo agência: valores correntes desembolsados (2009-2016)

(Em R\$ milhões correntes)

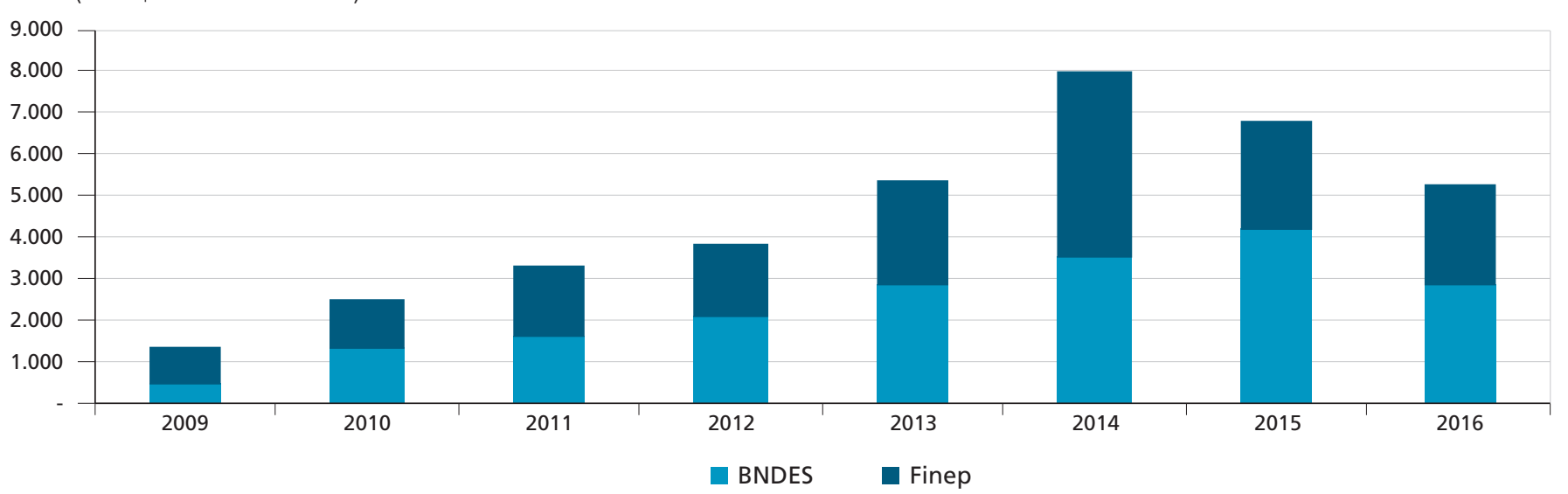

Fonte: Relatórios anuais da FINEP e do BNDES, disponíveis em: https://bit.ly/2xbLWu4, https://bit.ly/2LLCumQ e https://bit.ly/2JGhWLL. Acesso em: 22 abr. 2019. Elaboração dos autores.

1. Versão editada do texto originalmente publicado em DE NEGRI, J.; ARAÚJO, B.; BACELETTE, R. Financiamento do desenvolvimento no Brasil. Brasília: Ipea, 2018.

2. Tecnologista, coordenador de estudos em estratégias de crescimento das firmas na Diretoria de Estudos e Políticas Setoriais de Inovação e Infraestrutura (Diset) do Ipea.

3. Bolsista na Diset/lpea.

4. Doutorando em economia da indústria e da tecnologia na Universidade Federal do Rio de Janeiro (UFRJ) e assessor na Presidência da Financiadora de Estudos e Projetos (Finep). 
Do ponto de vista do BNDES, Machado, Martini e Gama (2017) ${ }^{5}$ comprovam que o crédito fornecido pelo banco para projetos de inovação aumenta a pesquisa e desenvolvimento (P\&D) das firmas beneficiárias em, no mínimo, 30\%. Por outro lado, poucos são os estudos recentes que avaliam os impactos do crédito concedido pela Finep a projetos de inovação.

O crédito concedido pela Finep pode ocorrer de forma direta, quando todo o processo de seleção, desembolso e acompanhamento é feito pela agência, ou de forma indireta, quando a agência repassa recursos para agentes regionais de fomento à inovação, atualmente via programa Inovacred.

De modo geral, as firmas beneficiárias do crédito direto são médias e grandes empresas com capacidades tecnológicas já estabelecidas e com certa liderança setorial, enquanto o crédito indireto é mais utilizado por pequenas empresas de base tecnológica de atuação recente e regional. Essa distinção é fundamental, uma vez que, no crédito direto (objeto desta avaliação), em geral, já na data da assinatura do contrato (que aqui consideramos como o início da intervenção de interesse), as empresas iniciam seus projetos de inovação, uma vez que, em geral, possuem musculatura financeira para tanto. Existem casos, inclusive, de empresas que iniciam seus projetos antes mesmo da contratação do crédito.

Dessa forma, este estudo avaliou em que medida o crédito direto da Finep impacta o esforço tecnológico das firmas beneficiárias. Isto é, em razão da tomada de crédito, as firmas beneficiárias somam recursos próprios àqueles obtidos com o Estado? Ou não, elas substituem os recursos próprios, que já seriam investidos em seu esforço tecnológico, pelos recursos públicos?

$\mathrm{Na}$ mesma linha dos mais recentes estudos nacionais e internacionais sobre adicionalidade das políticas de inovação, optou-se por avaliar os impactos do crédito direto da Finep a partir de um contrafactual. Isto é, realizou-se um quase experimento com o auxílio de grupo controle de firmas semelhantes que não receberam o tratamento, mas que apresentaram probabilidades semelhantes de serem beneficiadas pela intervenção.

Nesse sentido, a abordagem aqui selecionada comparou um grupo de firmas que recebeu o benefício, o qual se chama de tratamento, e um grupo de firmas que não recebeu, mas que poderia ter recebido o crédito subsidiado da Finep. Por sua vez, a intervenção de interesse diz respeito ao acesso ao crédito direto da Finep (assinatura do contrato) no período 2005-2014. Assim, a escolha para o referido período de análise justifica-se em razão da disponibilidade de dados fornecidos pela Finep e pela necessária contrapartida obtida na Relação Anual de Informaçôes Sociais (Rais), cujo último ano disponível identificado é 2015.

Para estimar o score de propensão necessário ao pareamento dos grupos tratamento e controle, utilizamos um modelo logit com emprego de variáveis de controle defasadas e selecionadas em funçáo das características da intervenção, da disponibilidade de dados, do que é usual nas avaliaçóes de impacto das políticas de inovação no Brasil, bem como de testes com outras variáveis disponíveis (quadro 1).

QUADRO 1

Variáveis utilizadas no pareamento

\begin{tabular}{|l|l|l|}
\hline \multicolumn{1}{|c|}{ Variável } & \multicolumn{1}{c|}{ Descrição } & \multicolumn{1}{c|}{ Base de dados } \\
\hline log(contratos) & Log natural do número total de funcionários & \\
\hline log(empr_anos) & Log natural da idade da firma em anos & $\begin{array}{l}\text { Relação Anual de Informações Sociais } \\
\text { (Rais) }\end{array}$ \\
\hline cnae2D & Código CNAE (2.0) dois dígitos & Número percentual de formados com terceiro grau sob PO total \\
\hline PO_TGrau_Percent & Região do país (categórica para as cinco regiões) & Banco Central do Brasil (BCB) \\
\hline Regiao & Origem estrangeira (dummy = 1 se sim) \\
\hline Multi ${ }^{1}$ & &
\end{tabular}

Elaboração dos autores.

Nota: ${ }^{1}$ Controle acima de $50 \%$ do capital define a origem.

5. MACHADO, L.; MARTINI, R. A.; GAMA, M. Does BNDES innovation credit boost firms' R\&D expenditures? Evidence from Brazilian panel data. Rio de Janeiro: BNDES, 2017. 
O algoritmo de pareamento empregado foi o do vizinho mais próximo sem repetição, restringindo a amostra à área de suporte comum, de forma muito semelhante a Czarnitzki e Hussinger (2018), ${ }^{6}$ com a única diferença de termos empregado um modelo logit e não probit, tal como os autores.

Realizando pareamentos por ano e considerando as características da intervenção, optou-se por realizar o pareamento das estreantes em $t$ - 1 e observar os resultados em $t+1$, de maneira a dar tempo suficiente para que o crédito obtido em $t$ fosse, em sua maior parte, recebido pelas firmas e tivesse tempo suficiente para provocar mudanças no comportamento dessas. É importante lembrar que a assinatura do contrato marca apenas o início da intervenção que se processa, mediante pagamento de parcelas ao longo de $t$ e $t+1$.

Depois de realizado o pareamento, o impacto foi observado por meio da análise empilhada dos parâmetros estimados por mínimos quadrados ordinários (ordinary least squares - OLS), nos quais o número do pessoal ocupado em áreas científicas e tecnológicas (Potec) e este em relação ao pessoal ocupado (PO) são as variáveis dependentes, ou seja, são as medidas de esforço de P\&D.

Assim sendo, a empresa estreante que assinou a contratação de crédito em 2005, por exemplo, será pareada a partir de suas características de 2004 e terá seus esforços observados em 2006, e assim por diante. Em outras palavras, o pareamento foi realizado no período anterior à intervenção e seus possíveis impactos observados em um período suficientemente posterior, atendendo, assim, às recomendaçóes de White e Sabarwal (2014). ${ }^{7}$

Para definir os impactos, foram observados dois indicadores de resultado: a diferença das taxas médias de crescimento percentual do Potec entre os grupos tratamento e controle (teste de hipótese) e a diferença entre as taxas médias de intensidade de Potec em relação ao PO total da empresa (qualificando o teste de hipótese). Assim, tem-se a variação no esforço em função da intervenção, bem como os possíveis efeitos dessa variação na intensidade tecnológica das firmas beneficiárias.

Idealmente, o esforço tecnológico é medido pelos gastos internos e externos em P\&D. No Brasil, tais gastos são coletados bianualmente pela Pesquisa de Inovação do Instituto Brasileiro de Geografia e Estatística (Pintec/IBGE). Nesse sentido, não existem dados para todos os anos do período de análise aqui pretendido. Adicionalmente, a última edição da Pintec apresenta dados, até 2014, insuficientes para cobrir a observação da totalidade dos impactos que vai até 2015 ( $t+1$ para firmas que tomaram crédito em 2014).

A utilização do Potec como proxy dos gastos internos e externos em P\&D empresarial é uma prática comum que se baseia na alta correlação entre o comportamento desses e o número de $\mathrm{PO}$ em tais atividades, tal como demonstrado em Araújo, Cavalcante e Alves (2009) ${ }^{8}$ e posteriormente confirmado em Shimada, Kannebley Júnior e De Negri (2014). ${ }^{9}$ Assim, confirmando essas correlaçôes, estatísticas internacionais mostram que a maior parte do investimento em P\&D é realizada justamente na contratação de pessoal qualificado.

Uma vez pareados os grupos tratamento e controle, o segundo passo consistiu em observar as diferenças nas variaçóes no Potec relativo e no Potec em relação ao PO total entre $t-1$ e $t+1$. Assim, construiu-se uma regressão OLS com apenas um parâmetro (a participação ou não na intervenção) e duas variáveis de resultado: i) $(($ Potec $t+1$-Potec $t-1) /($ Potec $t-1))$, que chamamos de esforço; e ii) $((\operatorname{Potec} t+1 /$ PO $t+1)-(\operatorname{Potec} t-1 /$ PO $t-1))$, que chamamos de intensidade.

6. CZARNITZKI, D.; HUSSINGER, K. Input and output additionality of R\&D subsidies. Applied Economics, v. 50, n. 12, p. 1324-1341, 2018.

7. WHITE, H.; SABARWAL, S. Quasi-experimental design and methods. New York: Unicef, 2014. (Methodological Briefs, n. 8).

8. ARAÚJO, B. C.; CAVALCANTE, L. R.; ALVES, P. Variáveis proxy para os gastos empresariais em inovação com base no pessoal ocupado técnico-científico disponível na Relação Anual de Informações Sociais (Rais). Radar: Tecnologia, Produção e Comércio Exterior, n. 5, p. 16-21, 2009.

9. SHIMADA, E.; KANNEBLEY JÚNIOR, S.; DE NEGRI, F. Efetividade da Lei do Bem no estímulo ao investimento em P\&D: uma análise com dados em painel. Rio de Janeiro: Anpec, 2014. 
TABELA 1

Resultados das estimativas por OLS com variância robusta, segundo parâmetros

\begin{tabular}{|c|c|c|}
\hline \multirow{2}{*}{ Estimadores } & \multicolumn{2}{|c|}{ Variáveis de resultado } \\
\hline & Esforço & Intensidade \\
\hline$\beta_{0}$ (variação média do grupo tratamento) & $1,0562^{* * *}$ & 0,001 \\
\hline$\beta_{1}$ (diferença das variações médias entre não tratados e tratados) & $-0,7637^{* * *}$ & $-0,008^{* *}$ \\
\hline
\end{tabular}

Elaboração dos autores.

Obs.: ${ }^{* *} \mathrm{e}^{* * *}=$ significantes a $5 \%$ e a $1 \%$, respectivamente.

O indicador de esforço mede a variação relativa média do Potec entre $t-1$ e $t+1$. A partir dele, é possível observar o crescimento médio do grupo tratamento e a diferença entre o crescimento relativo médio do grupo controle frente ao tratamento. A intensidade, por sua vez, mede a variação média da participação relativa do Potec frente ao pessoal empregado total da empresa entre $t-1$ e $t+1$, ou seja, demonstra a influência da variação do esforço na estrutura tecnológica da empresa.

Os resultados do modelo demostram que tanto as firmas do grupo tratamento quanto as do grupo controle aumentaram suas contrataçóes de Potec entre $t-1$ e $t+1$. Contudo, as firmas do grupo tratamento tiveram um crescimento relativamente maior nessas contrataçóes, fato este que nega ocorrência de full crowding-out.

Dessa maneira, do crescimento total das contrataçóes de Potec das empresas beneficiárias, existe uma parte que só pode ser explicada pela participação na intervenção. Segundo o estimador das diferenças, desse crescimento total, 76 pontos percentuais referem-se ao acesso ao crédito direto da Finep, pois é a única diferença observável entre os dois grupos.

Sendo assim, estima-se que o acesso ao crédito direto da Finep é responsável por elevar, em média, em 76\% a contratação de pessoal classificado como Potec de empresas com mais de dez empregados e que já possuíam algum esforço tecnológico. O restante do crescimento das contrataçóes de Potec, observadas no grupo tratamento, deve-se a outros fatores que não a intervenção (visto que também foram observados no grupo controle). A título ilustrativo, é relevante mencionar que o Potec médio das empresas beneficiadas pelo crédito direto da Finep, com Potec maior que 0 e PO maior que 10 em $t$-1, era de 59,21 empregados.

Por sua vez, mesmo esse crescimento não foi suficiente para elevar a intensidade tecnológica (percentual do Potec em relação ao PO total da empresa) das firmas beneficiárias. Ele apenas foi suficiente para garantir a manutenção das intensidades que, de outra forma, cairiam. Isso porque o estimador da intensidade média do grupo tratamento náo é diferente de 0 , ou seja, náo apresentou crescimento, mas as diferenças entre os grupos tratamento e controle são diferentes de 0 e significativas a 5\% (as intensidades do grupo controle caíram, enquanto as do grupo tratamento mantiveram-se constantes). Assim, pode-se afirmar que o acesso ao crédito direto da Finep, se não foi suficiente para elevar a intensidade tecnológica das firmas beneficiárias, evitou uma diminuição de, em média, quase 1 ponto percentual.

Finalmente, é relevante mencionar que os resultados aqui apontados estão em linha com os achados encontrados por Araújo et al. (2012) e outros ${ }^{10}$ que negam o efeito substituição. 

Ipea - Instituto de Pesquisa Econômica Aplicada

Assessoria de Imprensa e Comunicação

\section{EDITORIAL}

\section{Coordenação}

Ipea

\section{Revisão}

Editorar Multimídia

\section{Editoração}

Editorar Multimídia

Capa

Leonardo Hideki Higa

Imagens da Capa

Banco Freepik (freepik.com)

Projeto Gráfico

Renato Rodrigues Bueno

The manuscripts in languages other than Portuguese published herein have not been proofread.

\section{Livraria Ipea}

SBS - Quadra 1 - Bloco J - Ed. BNDES, Térreo

70076-900 - Brasília - DF

Tel.: (61) 20265336

Correio eletrônico: livraria@ipea.gov.br 




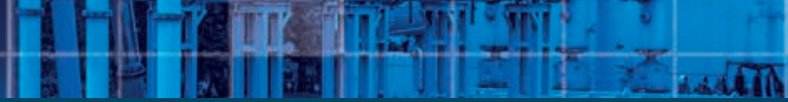

\section{Missão do Ipea}

Aprimorar as políticas públicas essenciais ao desenvolvimento brasileiro por meio da produção e disseminação de conhecimentos e da assessoria ao Estado nas suas decisões estratégicas.
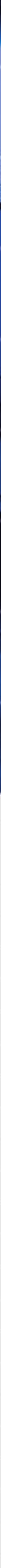